\title{
Türkiye Bina Deprem Yönetmeliğine Göre Mevcut Betonarme Binanın Performansının Ve Zemin Etkileşiminin Değerlendirilmesi
}

\author{
Mehmet Fatih Altan ${ }^{1}$, Sinan Cansız $^{2 *}$, Osman Kaya ${ }^{3}$, Çağatay Turna ${ }^{4}$ \\ Geliş / Received: 29/04/2020 \\ Revize / Revised: 22/09/2020 \\ Kabul / Accepted: 01/10/2020
}

\begin{abstract}
ÖZ
Dünyada yaygın olarak ulusal ve uluslararası yönetmeliklerde performansa dayalı tasarım prensipleri kullanılmaktadır. 1990'lı yıllarda meydana gelen depremler sonrası hasar alan yapıların tekrar kullanılamaması sebebiyle ağır ekonomik kayıplar yaşanmıştır. Sonrasında birçok yönetmelikte yapıların deprem sonrası kullanımı sağlanacak şekilde hedef performansa göre tasarımına yer verilmiştir. Türkiye Bina Deprem Yönetmeliğinin (TBDY) 2019 yılında yayımlanmasıyla birlikte yapı-zemin etkileşimine daha fazla önem verilmiştir. Bu doğrultuda ilk kez düşey yer hareketi spektrumu tanımlanarak kullanılmaya başlanmıştır. Ayrıca deprem tehlike haritaları yayınlanarak her bölge için spektral ivme katsayıları tanımlanmıştır. Bu çalışma kapsamında Türkiye Bina Deprem Yönetmeliğine göre mevcut betonarme bir binanın performans analizi yapılmıştır. Deprem Bölgelerinde Yapılacak Binalar Hakkında Yönetmelikte (2007) mevcut binaların performans analizinde şekil değiştirme esaslı yaklaşımlar tanımlanırken, TBDY-2019'da ilave olarak yeni binaların tasarımında da şekil değiştirme esaslı yaklaşımlara yer verilmiştir. Bu çalışma ile yeni yayınlanan yönetmeliğin uygulama esasları araştırılmıştır. Çalışmada TBDY-2019'a göre hesaplanmış düzensiz bir yapının performans durumu incelenmiştir. İnceleme sonucunda kontrollü hasar performans düzeyi hesaplanmış yapının yeni yönetmeliğe göre hesap detayları gösterilmiştir. Tüm aşamalarıyla anlatılan düzensiz yapıların performans analizi konusunda, çalışma sahasının genişletilmesinin uygun olacağı düşünülmektedir.
\end{abstract}

Anahtar Kelimeler- Deprem, İtme Analizi, Performans Analizi

1İletişim: mehmetaltan@aydin.edu.tr (https://orcid.org/0000-0003-0961-0115)

İnşaat Mühendisliği, İstanbul Aydın Üniversitesi, İstanbul

2*Sorumlu yazar iletişim: sinancansiz@aydin.edu.tr (https://orcid.org/0000-0001-6375-6487)

İnşaat Teknolojisi, İstanbul Aydın Üniversitesi, İstanbul

3Iletişim: ce.osmankaya@gmail.com (https://orcid.org/0000-0002-6533-949X)

Yüksek Lisans Öğrencisi, İstanbul Aydın Üniversitesi, İstanbul

4İletişim: turna.cagatay@gmail.com (https://orcid.org/0000-0003-3400-6999)

Yüksek Lisans Öğrencisi, İstanbul Aydın Üniversitesi, İstanbul 


\title{
Evaluation of the Performance and Ground Interaction of the Existing Reinforced Concrete Building According to Turkey Earthquake Building Regulations
}

\begin{abstract}
Performance-based design principles are widely used in national and international regulations in the world. Since the structures damaged after the earthquakes in the 1990s could not be reused, high economic losses were experienced. Later, in many design codes, the design of the buildings according to the target performance was provided so as to ensure the use of the buildings after the earthquake. Turkey Earthquake Building Code (TBDY) is given more importance to the soil-structure interaction with the release in 2018. Accordingly, the vertical ground motion spectrum has been defined and used for the first time. In addition, earthquake hazard maps were published and spectral acceleration coefficients were defined for each region. In this study, a performance analysis of the existing reinforced concrete buildings by the Building Turkey Earthquake Building Code is made. In the Code on Buildings to be built in Earthquake Zones (2007), deformation-based approaches are defined in the performance analysis of existing buildings, while in addition to TBDY-2018, deformationbased approaches are also included in the design of new buildings. With this study, the application principles of the newly published code were investigated. In the study, the performance state of an irregular structure calculated according to TBDY-2019 was examined. As a result of the examination, the calculation details of the structure, for which a controlled damage performance level was calculated, according to the TBDY-2019 code was shown. In terms of performance analysis of irregular structures, which are described in all stages, it is considered to be appropriate to expand this study field.
\end{abstract}

Keywords- Earthquake, Push-Over Analysis, Performance Analysis 


\begin{tabular}{|c|c|c|}
\hline & $\begin{array}{l}\text { BŞEÜ Fen Bilimleri Dergisi } \\
7(2), 1004-1014,2020\end{array}$ & $\begin{array}{r}\text { BSEU Journal of Science } \\
\text { DOI: } 10.35193 / \text { bseufbd. } 727437\end{array}$ \\
\hline & & 58-7575 (http://dergipark.gov.tr/bseufbd) \\
\hline
\end{tabular}

\section{I.GİRIŞ}

Dünyanın birçok bölgesi ve nüfusun yoğun yaşadığı yerleşim alanları deprem kuşağında yer almaktadır[1]. Bu bölgelerde her gün sayısız depremler kaydedilmektedir. Bunların büyüklüğünün küçük olması sebebiyle birçoğu hissedilmemektedir. Hissedilen büyük depremlerin önceden haber alınamaması veya tahmin edilememesi sebebiyle depreme dayanıklı yapı tasarımı alınacak en önemli tedbir olarak öne çıkmaktadır. Depreme dayanıklı yapı tasarımında dikkat edilmesi gereken önemli adımlar bulunmaktadır. Bu adımlar sırasıyla; taşıyıcı sistem seçimi, taşıyıcı sistemin doğru modellenmesi, depremin ve yer değiştirme spektrumunun doğru tanımlanması, sonuçların projelendirilmesi ve yapım sürecidir. Bu aşamalar içerisinde malzemenin elastik ötesi davranışını dikkate alan şekil değiştirme limitlerinin doğru tanımlanması ve değerlendirilmesi önem arz etmektedir [1]. 1990'lı yıllarda meydana gelen depremler sebebiyle yaşanan ekonomik kayıplar sonrası performansa dayalı tasarım fikri ön plana çıkmıştır. Performansa dayalı tasarım prensibine göre yapının maruz kalacağı deprem sonrası olması gereken durumu hedefleyen yaklaşımdır. Bu yaklaşımda hedef performans seviyesi şekil değiştirme sınır değerleri cinsinden tanımlanmaktadır. Önceki yıllarda yapılan tasarımlarda kullanılan kuvvet esaslı yaklaşımlarda deprem sırasında oluşan kesit tesirinden daha dayanıklı olması hedeflenmiştir [2]. Ancak deprem sonrası oluşan hasar durumu veya tekrar kullanımı önemsenmemiştir. Buna karşın her iki yaklaşımında ana hedefi plastik mafsalların kirişlerde olması sağlanarak kat mekanizmasının önüne geçmektir. Performansa dayalı tasarım prensibini uygulayan birçok yönetmelikte farklı yöntemler izlenmektedir. $\mathrm{Bu}$ yönetmeliklerin bazılarının birbirlerine göre daha üstün olduğu durumların olması ve tek bir doğruya ulaşılamamış olması, performansa dayalı tasarımın en önemli eksiklerindendir. Mevcut binaların değerlendirilmesi için kullanılan FEMA-273(1997), FEMA 356 (2000), ASCE 41-06 (2007) ve ATC-40 (1996) gibi standartlar yapıların performans düzeyini tanımlanan performans seviyelerine göre tahmin etmektedir [3], [4], [5], [6]. Türkiye Bina Deprem Yönetmeliği'nin Şekil Değiştirmeye Göre Değerlendirme ve Tasarım İlkeleri (ŞGDT) başlıklı 5.1. maddesinin ikinci bendinde, bu değerlendirme yaklaşımının uygulanacağ yapıları Yüksek Binalar, Depreme Yalıtımlı Binalar ve Mevcut Binaların Değerlendirilmesi ve Güçlendirilmesi olarak tanımlamıştır [7]. ŞGDT kapsamında; Yüksek Binalar, Mevcut Binaların Değerlendirilmesi Güçlendirilmesi ve Depreme Yalıtımlı Binalar için ayrı ayrı performans hedefleri bulunmaktadır. Bu alanda birçok araştırmacı tarafından çalışmalar ve yönetmelikler yapılmıştır [8], [9],[10],[11],[12]. Bu çalışmada mevcut bir binanın performans değerlendirilmesi yapılarak Tablo1'de gösterilen değerler esas alınarak performans hedefi belirlenmiş̧ir[7].

Tablo 1. Deprem tasarım sınıflarına göre yeni yapılacak veya mevcut binalar için performans hedefleri ve uygulanacak değerlendirme/tasarım yaklaşımları

\begin{tabular}{ccccc}
\hline \multirow{2}{*}{$\begin{array}{c}\text { Deprem } \\
\text { Yer H. }\end{array}$} & DTS=1,2,3,3a,4,4a & DTS=1a,2a \\
\cline { 2 - 5 } Düzeyi & Normal Performans & $\begin{array}{c}\text { Değerlendirme/Tasarım } \\
\text { Yaklaşımı }\end{array}$ & $\begin{array}{c}\text { Ileri } \\
\text { Performans } \\
\text { Hedefi }\end{array}$ & $\begin{array}{c}\text { Değerlendirme/Tasarım } \\
\text { Yaklaşımı }\end{array}$ \\
\hline DD-4 & KK & DGT & - & - \\
DD-3 & - & - & SH & ŞGDT \\
DD-2 & KH & DGT & KH & DGT \\
DD-1 & GÖ & ŞGDT & KH & ŞGT \\
\hline
\end{tabular}

\section{II.MATERYAL VE YÖNTEM}

Bu çalışmada İstanbul'da bulunan Deprem Bölgelerinde Yapılacak Binalar Hakkında Yönetmelik (2007) kapsamında tasarlanan bir binanın taşıyıcı sisteme ait elemanların belirlenmesi, zemin emniyet gerilmeleri, hesaplarda kullanılacak mevcut taşıyıcı sistem kesitlerine ait parametreler, taşıyıcı sistemin geometrisi, malzeme özellikleri detaylı olarak incelenerek performans seviyesi araştırılmıştır [13]. Yapıdan elde edilen bilgiler 6306 sayılı yasa kapsamında toplanmaktadır [14]. 


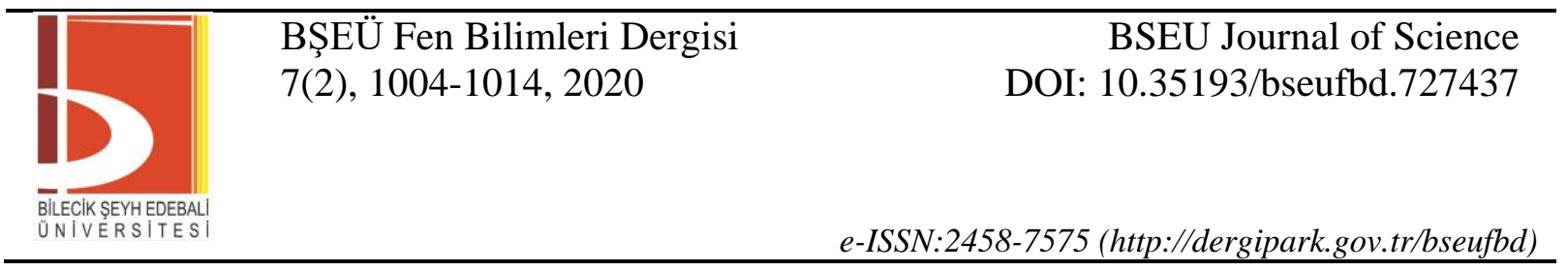

\section{A. Yaplya Ait Bilgiler}

Yapım yılı 2010, kullanım amacı konut ve betonarme çerçeveden oluşan bina tasarım depremi DD-2 ve Yerel Zemin Sınıfı ZD olarak belirlenmiştir. 2 Bodrum + Zemin +4 Normal Kat + Çatı Katından müteşekkil binanın kat yüksekliği 3,10mt/2,90mt'den oluşmakta olup, taban alanı $782,60 \mathrm{~m}^{2}$, toplam inşaat alanı ise $6.725,08 \mathrm{~m}^{2}$ 'dir. Yapıya ait kat planı Şekil 1'de gösterilmektedir. Binaya ait bilgi düzeyi kapsamlı (1.0) olarak tespit edilmiştir. TBDY-2019'agöre hesaplanan deprem parametreleri Tablo 2'de özetlenmiştir.

Tablo 2. TBDY-2019'a göre hesaplanmış deprem parametreleri

\begin{tabular}{ccccc}
\hline Hesap Yöntemi & \multicolumn{3}{c}{ Değer } \\
\hline Türkiye Deprem Haritaları [5] & $\mathrm{S}_{\mathrm{s}}$ & $\mathrm{S}_{1}$ & $\mathrm{PGA}$ & PGV \\
& 0,989 & 0,272 & 0,408 & 24,991 \\
TBDY-Zemin Değerleri & $\mathrm{S}_{\mathrm{s}}$ & $\mathrm{F}_{\mathrm{s}}$ & $\mathrm{S}_{1}$ & $\mathrm{~F}_{1}$ \\
& 0,989 & 1,104 & 0,272 & 2,056 \\
& \multicolumn{2}{c}{$\mathrm{S}_{\mathrm{DS}}$} & & \multicolumn{2}{c}{$\mathrm{S}_{\mathrm{D} 1}$} \\
Tasarım Spektral İvme K. & \multicolumn{2}{c}{1,092} & & \multicolumn{2}{c}{0,559} \\
$\mathrm{~T}_{\mathrm{A}}$ & $\mathrm{T}_{\mathrm{B}}$ & & $\mathrm{T}_{\mathrm{L}}$ \\
(s) & 0,102 & 0,512 & \multicolumn{2}{c}{6,000} \\
TBDY 2019Yatay Elastik Tasarım Spektrumu & $\mathrm{T}_{\mathrm{AD}}$ & $\mathrm{T}_{\mathrm{BD}}$ & \multicolumn{2}{c}{$\mathrm{T}_{\mathrm{LD}}$} \\
Düşey Elastik Tasarım Spektrumu & 0,034 & 0,171 & \multicolumn{2}{c}{3,000} \\
\hline
\end{tabular}

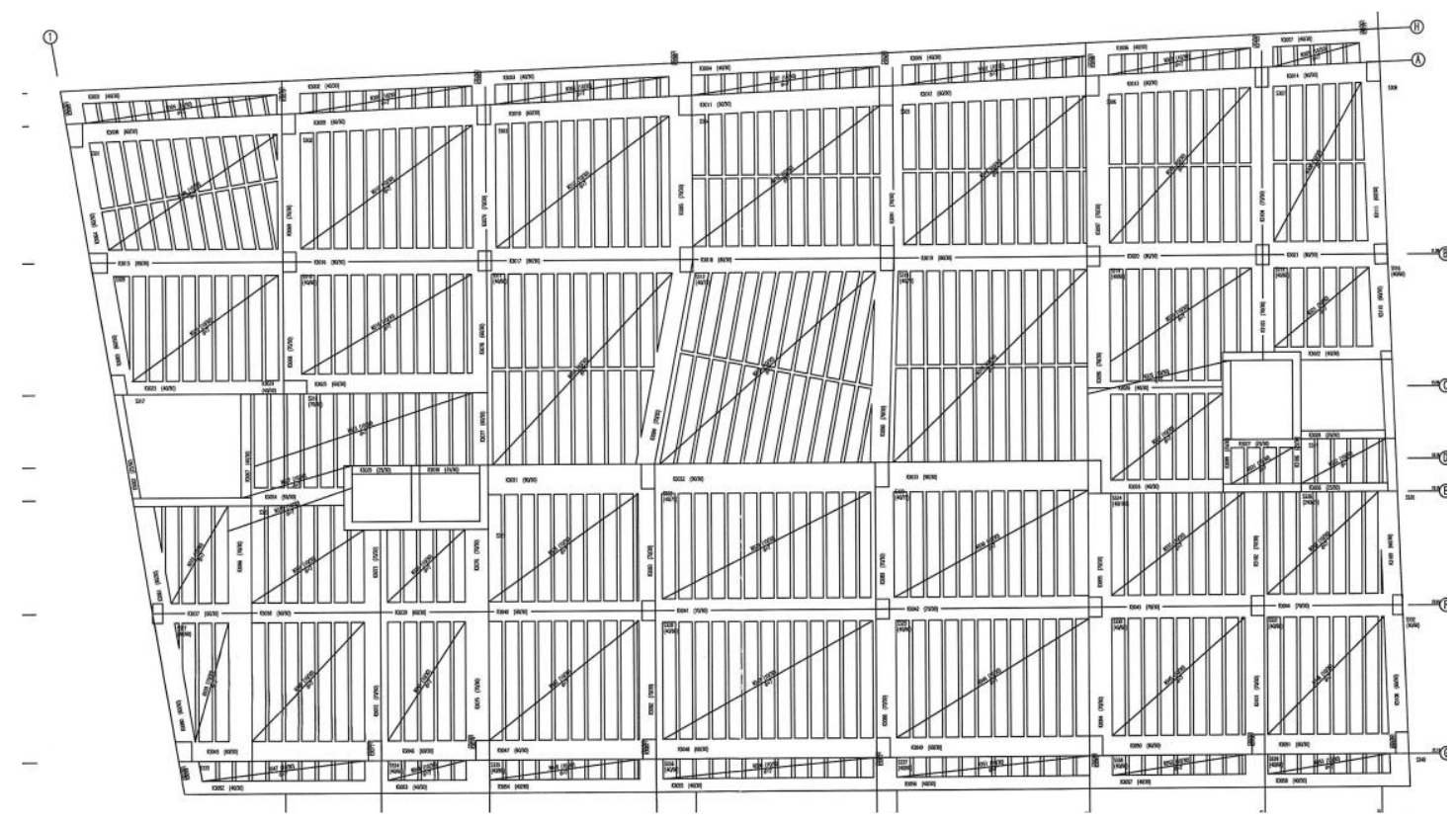

Şekil 1. Yapının bilgisayar programında modellenmiş kat planı

Yapının deprem etkileri altında performansını belirlenmesi amacıyla, yapının mimari, statik projeleri temin edilerek aşağıda maddeler halinde verilen işlemler uygulanmıştır.

- Taşıyıcı elemanlarında karot alınması,

- Beton dayanımının tespiti,

- Röntgen cihazı ile kolonların donatı çap ve adetlerinin tespiti,

- Donatı çap-adet tespiti ve etriye aralıklarının sıyırma metodu ile yapılarak kontrollerinin sağlanması.

Bu çalışmada Ek-1'de gösterilen yapı üç boyutlu modellenerek statik/performans analizi yapılmış ve performans seviyesi belirlenmiştir. Statik projeden belirlenen malzeme özellikleri ve hesap parametreleri Tablo 3'de özetlenmiş̧ir [15]. 


\begin{tabular}{|c|c|c|}
\hline & $\begin{array}{l}\text { BŞEÜ Fen Bilimleri Dergisi } \\
7(2), 1004-1014,2020\end{array}$ & $\begin{array}{l}\text { BSEU Journal of Science } \\
\text { DOI: } 10.35193 / \text { bseufbd } 727437\end{array}$ \\
\hline $\begin{array}{l}\text { BliLECIISSEYHEDEALI } \\
\text { ONIVERSITESI }\end{array}$ & & 58-7575 (http://dergipark.gov.tr/bseufbd) \\
\hline
\end{tabular}

Tablo 3. Malzeme özellikleri ve hesap parametreleri

\begin{tabular}{cc}
\hline Parametre & Değeri \\
\hline Beton Dayanımı (MPa) & 35 \\
Donatı Çelik Sınıfı & BÇ III- S420 \\
Yerel Zemin Sınıfi & ZD \\
Tasarım Depremi & DD-2 \\
Yapı Davranış Katsayısı & R=4 \\
Performans Analizi Katsayısı & R=1 \\
Hareketli Yük Katilim Katsayısı & 0,3 \\
Bina Önem Katsayısı & 1 \\
\hline
\end{tabular}

Betonarme yapıların performans analizinde beton dayanımının tespiti önem arz etmektedir. Beton dayanımının tespiti için tahribatlı ve tahribatsız yöntemler olmak üzere iki metod bulunmaktadır. Bu amaçla yapının beton dayanımının tespiti amacıyla her iki yöntemde kullanılmışıı[16].

\section{B. Yerinde Yaptlan Tespit ve Testler}

Betonarme yapının donatı durumunu tespit etme amacıyla binada tahribatsız yöntemler kullanılmıştır. Bu amaçla donatı tespit cihazı yardımı ile yapılan tespit sonucu elde edilen donatı oranları ve çapları Tablo 4'te gösterilmektedir.

Tablo 4. Kolon donatı oranları

\begin{tabular}{|c|c|c|c|c|c|c|}
\hline Kolon Adı & $\begin{array}{c}\mathbf{b} \\
(\mathbf{m m})\end{array}$ & $\begin{array}{c}\text { h } \\
(\mathbf{m m})\end{array}$ & $\begin{array}{c}\mathbf{d}^{\prime} \\
(\mathbf{m m})\end{array}$ & $\begin{array}{c}\phi \\
(\mathbf{m m})\end{array}$ & $\begin{array}{c}\mathbf{n} \\
\text { (adet) }\end{array}$ & $\rho_{t}$ \\
\hline $\mathrm{K} 1$ & 400 & 600 & 30 & 18 & 14 & 0,0148 \\
\hline $\mathrm{K} 2$ & 400 & 600 & 30 & 18 & 14 & 0,0148 \\
\hline $\mathrm{K} 3$ & 400 & 600 & 30 & 18 & 14 & 0,0148 \\
\hline K4 & 400 & 750 & 30 & 18 & 18 & 0,0145 \\
\hline K5 & 400 & 750 & 30 & 18 & 18 & 0,0145 \\
\hline K6 & 700 & 400 & 30 & 18 & 18 & 0,0145 \\
\hline K7 & 300 & 600 & 30 & 18 & 14 & 0,0148 \\
\hline K8 & 400 & 1000 & 30 & 18 & 22 & 0,0140 \\
\hline K9 & 400 & 1000 & 30 & 18 & 22 & 0,0140 \\
\hline
\end{tabular}

Mevcut taşıyıcı elemanlarının beton dayanımını tespit etme amacıyla tahribatlı yöntemlerden birisi olan karot alma yöntemi kullanılmıştır. Bu amaçla TS EN 12903-3 ve TS-EN 12504-1 standartlarına göre yeter sayıda yapılan karot alma işlemi Tablo 5 'te özetlenmiştir.

Tablo 5. Kolon karot testi sonuçları

\begin{tabular}{cccccc}
\hline \multirow{2}{*}{$\begin{array}{c}\text { Karot } \\
\text { No }\end{array}$} & Karot Yeri & $\begin{array}{c}\text { Karot } \\
\text { Capı } \\
(\mathbf{m m})\end{array}$ & $\begin{array}{c}\text { Yüksekliği } \\
(\mathbf{m m})\end{array}$ & $\begin{array}{c}\text { Kırılma Yükü } \\
(\mathbf{N})\end{array}$ & $\begin{array}{c}\text { Basınç Mukavemeti } \\
(\mathbf{M P a})\end{array}$ \\
\hline 1 & & 90 & 90 & 287600 & 45,2 \\
2 & 2.Bodrum Kat Kolon K1 & 90 & 90 & 256800 & 40,4 \\
3 & 2.Bodrum Kat Kolon K2 & 90 & 90 & 245700 & 38,6 \\
4 & 1.Bodrum Kat Kolon K3 & 90 & 90 & 282460 & 44,4 \\
5 & 1.Bodrum Kat Kolon K4 & 90 & 90 & 262103 & 41,2 \\
6 & 2.Normal Kat Kolon K5 & 90 & 90 & 251288 & 39,5 \\
7 & Normal Kat Kolon K6 & 90 & 90 & 265920 & 41,8 \\
8 & Normal Kat Kolon K7 & 90 & 90 & 269737 & 42,4 \\
9 & Normal Kat Kolon K8 & 90 & 90 & 248743 & 39,1 \\
\hline \multicolumn{7}{c}{ Normal Kat Kolon K9 } & \multicolumn{3}{c}{} \\
\hline
\end{tabular}




\begin{tabular}{|c|c|c|}
\hline & $\begin{array}{l}\text { BŞEÜ Fen Bilimleri Dergisi } \\
7(2), 1004-1014,2020\end{array}$ & $\begin{array}{r}\text { BSEU Journal of Science } \\
\text { DOI: } 10.35193 / \text { bseufbd. } 727437\end{array}$ \\
\hline $\begin{array}{l}\text { BüLCIKSEYHEDEBALI } \\
\text { UNIVERSITESI }\end{array}$ & & 58-7575 (http://dergipark.gov.tr/bseufbd) \\
\hline
\end{tabular}

Donatı tespit cihazı yardımıyla kolonlarda görülen donatıların yerinde tespiti amacıyla kolonlarda kabul betonu sıyrılarak donatılar ortaya çıkarılmıştır. Bu yöntem ile donatılarda meydana gelen korozyon seviyesi belirlenmiştir. Bu yapılan işlem Şekil 2'de ayrıntılı olarak gösterilmektedir. Donatı sıyırma sonrası elde edilen sonuçlar Tablo 6' da gösterilmektedir.
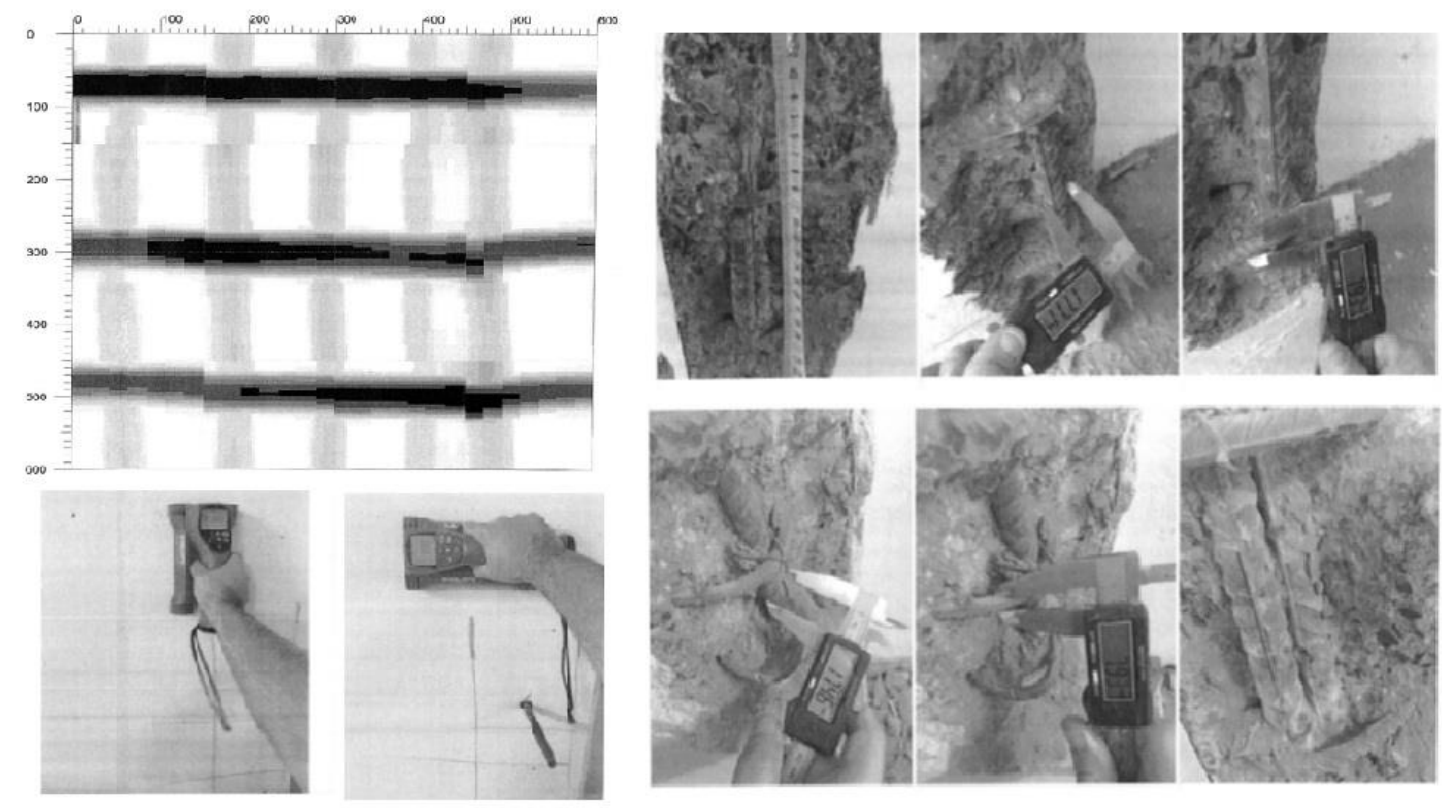

Şekil 2. Donatı tespiti işlemi

Tablo 6. Kolonlara ait donatı sıyırma tespiti

\begin{tabular}{|c|c|c|c|c|c|c|}
\hline \multirow[b]{2}{*}{ Sira No } & \multirow[b]{2}{*}{ Kolon Adı } & \multirow{2}{*}{$\begin{array}{c}\text { Proje } \\
\text { donatısı Çapı }\end{array}$} & \multicolumn{3}{|c|}{ Donatı Tespiti } & \multirow[b]{2}{*}{ Korozyon } \\
\hline & & & $\begin{array}{c}\phi_{\mathrm{t}} \\
(\mathbf{m m})\end{array}$ & $\begin{array}{c}\phi_{\mathrm{s}} \\
(\mathrm{mm})\end{array}$ & $\begin{array}{c}\mathrm{s} \\
(\mathrm{mm})\end{array}$ & \\
\hline 1 & $\mathrm{~K} 1$ & 18 & 17,71 & 8 & 170 & Yok \\
\hline 2 & $\mathrm{~K} 2$ & 18 & 17,98 & 8 & 90 & Yok \\
\hline 3 & $\mathrm{~K} 3$ & 18 & 17,46 & 8 & 100 & Yok \\
\hline 4 & K4 & 18 & 17,67 & 8 & 110 & Yok \\
\hline 5 & K5 & 18 & 17,86 & 8 & 80 & Yok \\
\hline 6 & K6 & 18 & 17,19 & 8 & 90 & Yok \\
\hline 7 & K7 & 18 & 17,58 & 8 & 70 & Yok \\
\hline 8 & K8 & 18 & 17,65 & 8 & 110 & Yok \\
\hline 9 & K9 & 18 & 17,94 & 8 & 100 & Yok \\
\hline
\end{tabular}

Burada $\phi_{\mathrm{t}}$ boyuna donatı çapını, $\phi_{\mathrm{s}}$ enine donatı çapını ve s etriye aralığını ifade etmektedir. Tahribatsız yöntemlerden birisi olan test çekici ile beton dayanım tespiti yapılabilmektedir. Bu yöntem karot ile dayanım tespitine göre daha güvensiz olmakla birlikte ön hazırlık amacı ile yapılan bir işlemdir. Bu yapıda kolon test çekicinden elde edilen sonuçlar Tablo 7'de sunulmaktadır. 
Tablo 7. Kolon test çekici sonuçları

\begin{tabular}{ccccccccccccc}
\hline No & Kolon Ad1 & \multicolumn{9}{c}{ Beton Test Çekici Geri Tepme Değerleri $\left(\mathrm{R}_{\mathrm{m}}\right)$} & \multicolumn{1}{c}{$\mathrm{R}_{\text {ort. }}$} \\
\hline 1 & 2.BodrumKatKolonK2 & 55 & 56 & 56 & 56 & 57 & 56 & 57 & 56 & 55 & 56 & 56 \\
2 & 2.BodrumKatKolonK2 & 52 & 51 & 52 & 52 & 52 & 52 & 52 & 54 & 54 & 54 & 52.5 \\
3 & 1.BodrumKatKolonK3 & 51 & 50 & 50 & 52 & 51 & 50 & 50 & 52 & 51 & 52 & 51 \\
4 & 1.BodrumKatKolonK4 & 59 & 59 & 58 & 59 & 57 & 59 & 58 & 59 & 58 & 57 & 58.3 \\
5 & 2.NormalKatKolonK5 & 57 & 57 & 59 & 58 & 59 & 60 & 60 & 59 & 59 & 60 & 58.8 \\
6 & NormalKatKolonK6 & 59 & 59 & 60 & 59 & 58 & 57 & 59 & 59 & 60 & 59 & 58.9 \\
7 & NormalKatKolonK7 & 58 & 59 & 58 & 59 & 58 & 59 & 58 & 59 & 58 & 58 & 58.4 \\
8 & NormalKatKolonK8 & 56 & 57 & 58 & 57 & 58 & 57 & 58 & 58 & 57 & 58 & 57.6 \\
9 & NormalKatKolonK9 & 59 & 57 & 59 & 58 & 58 & 57 & 58 & 59 & 58 & 59 & 58.2 \\
\hline
\end{tabular}

\section{III.PERFORMANS ANALİŻ}

Yapıya ait statik projelerden ve saha çalışmalarından elde edilen verilere TBDY (2019) kapsamında performans analizi STA4CAD programı yardımıyla yapılmıştır. Bu amaçla yapı mevcut malzeme dayanımları altında mevcut statik projesine uygun olarak STA4CAD programında modellenmiştir [17]. Programda TBDY (2018)'e göre deprem parametreleri veri giriş ekranına girilmiştir. Yapıdan alınan karot sonuçlarına göre tespit edilen malzeme dayanımları ile sistem modellenmiş̧ir. Yapının 2010 yılında imal edilmiş olması sebebiyle çatlamış kesite göre analizi yapılmıştır. TBDY'e göre betonarme elemanlar için tanımlanmış malzeme birim şekil değiştirme sınır değerleri 1-5 denklemlerinde verilmektedir.

$$
\begin{aligned}
& \varepsilon_{c}^{(G \ddot{)})}=0.0035+0.07 \sqrt{\omega_{w c}} \leq 0.01 \\
& \varepsilon_{s}^{(G \ddot{)})}=0.4 \varepsilon_{s u} \\
& \theta_{p}^{(G \ddot{)})}=\frac{2}{3}\left[\left(\emptyset_{u}-\emptyset_{y}\right) L_{p}\left(1-0.5 \frac{L_{p}}{L_{s}}\right)+4.5 \emptyset_{u} d_{b}\right] \\
& \theta_{p}^{(K H)}=0.75 \theta_{p}^{(G \ddot{O})} \\
& \theta_{p}^{(S H)}=0
\end{aligned}
$$

Burada; $\varepsilon_{\mathrm{c}}$ en dış beton basınç lifindeki kısılmayı, $\omega_{\mathrm{wc}}$ enine donatı mekanik indeksi, $\varepsilon_{\mathrm{s}}$ boyuna donatıya ait birim uzama, $\varepsilon_{\mathrm{su}}$ boyuna donatıya ait maksimum gerilme anındaki birim uzama, $\theta_{\mathrm{p}}$ elemana ait plastik dönme oranını, $\emptyset_{\mathrm{u}}$ kesite ait maksimum eğriliği, $\emptyset_{\mathrm{y}}$ kesite ait akma eğriliğini, $\mathrm{L}_{\mathrm{p}}$ plastik mafsal boyunu, $\mathrm{L}_{\mathrm{s}}$ kolon boyunu ve $d_{b}$ boyuna donatı çapını ifade etmektedir.

Performans analizi sırasında kullanılan yazılım ile yapıya uygulanan eşdeğer deprem yükü yöntemi ile tüm yapi elemanlarında oluşan şekil değiştirme değerleri 1-5 denklemleri ile karş̧laştırılarak performans seviyeleri ölçülmüştür. TBDY (2019)'a göre tanımlanan hasar bölgeleri Şekil 2'de gösterilmektedir.

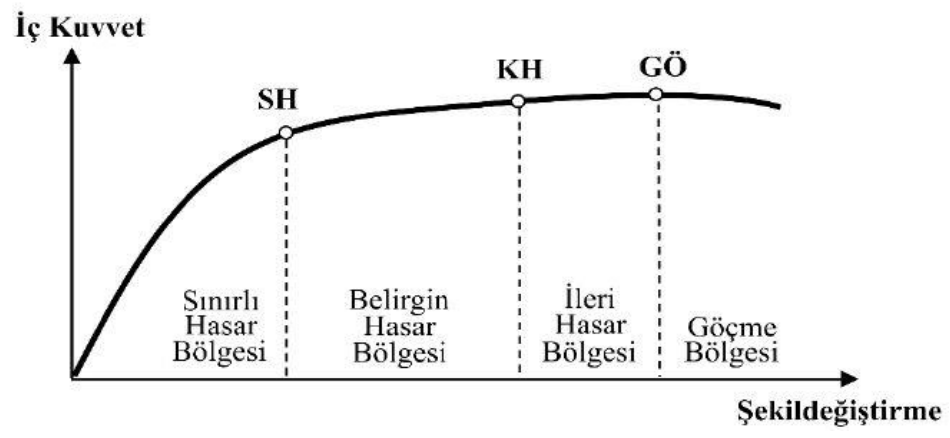

Şekil 3. TBDY göre hasar sınırları 
TBDY'de mevcut binalara ait deprem etkilerinin incelenmesi için gerekli kurallar Bölüm 15'de kapsamlı olarak tanımlanmıştır. Hesap yöntemleri için doğrusal ya da doğrusal olmayan hesap yöntemleri seçilebileceği ve bu yöntemler sonucunda şekil değiştirme sınırları belirlenerek deprem performans düzeyinin belirleneceği belirtilmektedir. Bu çalışmada incelenen yapının konut olması sebebiyle BKS=3, DD-2 deprem yer hareket düzeyindeki Normal Performans Hedefinin "Kontrollü Hasar” olduğu görülmüştür.

Kontrollü Hasar Performans Düzeyinde olması beklenen, olası bir deprem etkisi altında önceliğin can güvenliğinin sağlanması kaydıyla, yapının taşıyıcı sisteminde çok ağır olmamakla birlikte onarılması mümkün yapı hasarlarının oluşabileceği kabul edilmektedir. Mevcut Binalarda Kontrollü Hasar Performans Düzeyini TBDY'e göre sağlaması gereken koşullar maddeler halinde sıralanmıştır.

- Betonarme binaların herhangi bir katında, uygulanan her bir deprem doğrultusu için yapılan hesap sonucunda, ikincil (yatay yük taşıyıcı sisteminde yer almayan) kirişler hariç olmak üzere, kirişlerin en fazla \%35'i ve düşey elemanların (kolonlar, perdeler ve güçlendirilmiş bölme duvarlar) aşağıdaki paragrafta tanımlanan kadarı İleri Hasar Bölgesi'ne geçebilir. Çelik ve prefabrike betonarme binalarda bu istisnalar geçerli değildir. Her kattaki ileri hasar seviyesinde bulunan düşey taşıyıcı elemanlar tarafından taşınan taban kesme kuvvetinin \%20’yi geçmemesi, en üst kattaki kesme kuvveti toplamının ise \% 40 ' 1 geçmemesi,

- İleri Hasar Bölgesi’ndeki düşey elemanların, her bir katta düşey elemanlar tarafından taşınan kesme kuvvetine toplam katkısı \%20'nin altında olmalıdır. En üst katta İleri Hasar Bölgesi'ndeki düşey elemanların kesme kuvvetleri toplamının, o kattaki tüm düşey elemanların kesme kuvvetlerinin toplamına oranı en fazla \%40 olabilir.

- Diğer taşıyıcı elemanların tümü Sınırlı Hasar Bölgesi veya Belirgin Hasar Bölgesi’ndedir. Ancak, herhangi bir katta alt ve üst kesitlerinin ikisinde birden Belirgin Hasar Sınırı aşılmış olan düşey elemanlar tarafından taşınan kesme kuvvetlerinin, o kattaki tüm düşey elemanlar tarafından taşınan kesme kuvvetine oranının \%30’u aşmaması gerekir (Doğrusal yöntemle hesapta, alt ve üst düğüm noktalarının ikisinde birden Denk.(7.3)'ün sağlandığı kolonlar bu hesaba dahil edilmezler).

- Yapının doğrusal analizi sonrası elde edilen sonuçlara göre kolonlarda, kirişlerde ve diğer kesitlerde oluşan hasar yüzdeleri Tablo 9-11'de gösterilmektedir.

Tablo 9. Kiriş hasar yüzdeleri

\begin{tabular}{|c|c|c|c|c|c|c|c|c|c|c|c|c|c|c|c|c|}
\hline \multirow{2}{*}{ Kat No } & \multicolumn{4}{|c|}{$(-X)$} & \multicolumn{4}{|c|}{$(+X)$} & \multicolumn{4}{|c|}{$(-Y)$} & \multicolumn{4}{|c|}{$(+Y)$} \\
\hline & SH & BH & IH & GB & SH & BH & IH & GB & SH & BH & IH & GB & SH & BH & IH & GB \\
\hline 9 & 100 & 0,0 & 0,0 & 0,0 & 100 & 0,0 & 0,0 & 0,0 & 0,0 & 0,0 & 0,0 & 0,0 & 0,0 & 0,0 & 0,0 & 0,0 \\
\hline 8 & 98,3 & 1,7 & 0,0 & 0,0 & 100 & 0,0 & 0,0 & 0,0 & 92,6 & 7,4 & 0,0 & 0,0 & 88,9 & 11,1 & 0,0 & 0,0 \\
\hline 7 & 94,8 & 5,2 & 0,0 & 0,0 & 98,3 & 1,7 & 0,0 & 0,0 & 83,3 & 16,7 & 0,0 & 0,0 & 85,2 & 14,8 & 0,0 & 0,0 \\
\hline 6 & 94,8 & 5,2 & 0,0 & 0,0 & 100 & 0,0 & 0,0 & 0,0 & 92,6 & 7,4 & 0,0 & 0,0 & 85,2 & 14,8 & 0,0 & 0,0 \\
\hline 5 & 93,1 & 6,9 & 0,0 & 0,0 & 100 & 0,0 & 0,0 & 0,0 & 88,9 & 11,1 & 0,0 & 0,0 & 85,2 & 14,8 & 0,0 & 0,0 \\
\hline 4 & 94,8 & 5,2 & 0,0 & 0,0 & 98,3 & 1,7 & 0,0 & 0,0 & 88,9 & 11,1 & 0,0 & 0,0 & 88,9 & 11,1 & 0,0 & 0,0 \\
\hline 3 & 91,4 & 8,6 & 0,0 & 0,0 & 98,3 & 1,7 & 0,0 & 0,0 & 94,4 & 5,6 & 0,0 & 0,0 & 83,3 & 16,7 & 0,0 & 0,0 \\
\hline 2 & 97,3 & 2,7 & 0,0 & 0,0 & 94,6 & 5,4 & 0,0 & 0,0 & 100 & 0,0 & 0,0 & 0,0 & 100 & 0,0 & 0,0 & 0,0 \\
\hline 1 & 100 & 0,0 & 0,0 & 0,0 & 96,6 & 3,4 & 0,0 & 0,0 & 100 & 0,0 & 0,0 & 0,0 & 100 & 0,0 & 0,0 & 0,0 \\
\hline
\end{tabular}


Tablo 10. Kolon hasar yüzdeleri

\begin{tabular}{|c|c|c|c|c|c|c|c|c|c|c|c|c|c|c|c|c|}
\hline \multirow{2}{*}{$\begin{array}{c}\text { Kat } \\
\text { No }\end{array}$} & \multicolumn{4}{|c|}{$(-X)$} & \multicolumn{4}{|c|}{$(+X)$} & \multicolumn{4}{|c|}{$(-Y)$} & \multicolumn{4}{|c|}{$(+\mathbf{Y})$} \\
\hline & SH & BH & IH & GB & SH & BH & IH & GB & SH & BH & IH & GB & SH & BH & IH & GB \\
\hline 9 & 100 & 0,0 & 0,0 & 0,0 & 100 & 0,0 & 0,0 & 0,0 & 100 & 0,0 & 0,0 & 0,0 & 100 & 0,0 & 0,0 & 0,0 \\
\hline 8 & 100 & 0,0 & 0,0 & 0,0 & 100 & 0,0 & 0,0 & 0,0 & 100 & 0,0 & 0,0 & 0,0 & 93,7 & 6,3 & 0,0 & 0,0 \\
\hline 7 & 100 & 0,0 & 0,0 & 0,0 & 100 & 0,0 & 0,0 & 0,0 & 100 & 0,0 & 0,0 & 0,0 & 100 & 0,0 & 0,0 & 0,0 \\
\hline 6 & 100 & 0,0 & 0,0 & 0,0 & 100 & 0,0 & 0,0 & 0,0 & 100 & 0,0 & 0,0 & 0,0 & 100 & 0,0 & 0,0 & 0,0 \\
\hline 5 & 100 & 0,0 & 0,0 & 0,0 & 100 & 0,0 & 0,0 & 0,0 & 100 & 0,0 & 0,0 & 0,0 & 100 & 0,0 & 0,0 & 0,0 \\
\hline 4 & 100 & 0,0 & 0,0 & 0,0 & 100 & 0,0 & 0,0 & 0,0 & 99,8 & 0,2 & 0,0 & 0,0 & 100 & 0,0 & 0,0 & 0,0 \\
\hline 3 & 100 & 0,0 & 0,0 & 0,0 & 92,5 & 7,5 & 0,0 & 0,0 & 88,6 & 11,4 & 0,0 & 0,0 & 94,5 & 5,5 & 0,0 & 0,0 \\
\hline 2 & 100 & 0,0 & 0,0 & 0,0 & 92,5 & 4,5 & 0,0 & 0,0 & 100 & 0,0 & 0,0 & 0,0 & 100 & 0,0 & 0,0 & 0,0 \\
\hline 1 & 100 & 0,0 & 0,0 & 0,0 & 100 & 0,0 & 0,0 & 0,0 & 100 & 0,0 & 0,0 & 0,0 & 100 & 0,0 & 0,0 & 0,0 \\
\hline
\end{tabular}

Tablo 11. Alt ve üst kesitlerde sınırlı hasar bölgesini aşan kolonların kesme kuvveti dağılımı

\begin{tabular}{|c|c|c|c|c|c|c|c|c|}
\hline \multirow{2}{*}{$\begin{array}{c}\text { Kat } \\
\text { No }\end{array}$} & \multicolumn{2}{|c|}{$(-X)$} & \multicolumn{2}{|c|}{$(+X)$} & \multicolumn{2}{|c|}{$(-Y)$} & \multicolumn{2}{|c|}{$(+Y)$} \\
\hline & $\mathrm{SH}+\mathrm{BH}$ & IH+GB & $\mathrm{SH}+\mathrm{BH}$ & IH+GB & SH & BH+IH+GB & SH & $\mathrm{BH}+\mathrm{IH}+\mathrm{GB}$ \\
\hline 9 & 100 & 0,0 & 100 & 0,0 & 100 & 0,0 & 100 & 0,0 \\
\hline 8 & 100 & 0,0 & 100 & 0,0 & 100 & 0,0 & 100 & 0,0 \\
\hline 7 & 100 & 0,0 & 100 & 0,0 & 100 & 0,0 & 100 & 0,0 \\
\hline 6 & 100 & 0,0 & 100 & 0,0 & 100 & 0,0 & 100 & 0,0 \\
\hline 5 & 100 & 0,0 & 100 & 0,0 & 100 & 0,0 & 100 & 0,0 \\
\hline 4 & 100 & 0,0 & 100 & 0,0 & 100 & 0,0 & 100 & 0,0 \\
\hline 3 & 100 & 0,0 & 100 & 0,0 & 100 & 0,0 & 100 & 0,0 \\
\hline 2 & 100 & 0,0 & 100 & 0,0 & 100 & 0,0 & 100 & 0,0 \\
\hline 1 & 100 & 0,0 & 100 & 0,0 & 100 & 0,0 & 100 & 0,0 \\
\hline
\end{tabular}

TBDY' göre tasarım yapılırken zemin koşullarını, depremsellik durumu ve yapı zemin ilişkisini dikkate alınmaktadır. Temelin Taşıma gücü, temel oturması, yatayda kayma, şişme ve sıkışma durumlarının analiz edilmesi gerekmektedir. Bu doğrultuda geoteknik rapor için sismik analiz ve sondaj yapılarak elde edilen sonuçlar dikkate alındığında zeminin taşıma gücü belirlenmiştir. Sismik analizde, MASW yöntemi daha sınırlı derinliğine sahip olmasının yanında, sı̆̆ zemin araştırmalarında da kullanılmaktadır [18]. MASW analizi sonucunda 1.tabakada emniyetli taşıma gücü $1,02 \mathrm{~kg} / \mathrm{cm}^{2}$ iken 2 . tabakada emniyetli taşıma gücü $4,18 \mathrm{~kg} / \mathrm{cm}^{2}$ ' ye çıkmıştır. Arazi incelemeleri sonrasında zemin ile ilgili verileri doğrulamak için zemine dönel tip sondaj yapılmıştır. Arazide 2 adet sondaj yapılmış olup, zemin TS EN ISO 22476-3 standardına göre litolojisini, düşey yöndeki değişimi ve yeraltı suyu seviyesi durumuna bakılmıştır. Sondaj çalışması sonucunda, 0-4 m arasında dolgu malzemesi ve 4-8 m arasında kumlu siltli kile rastlanması sebebiyle Presiometre deneyleri yapılmamıştır. SK-1 kuyusundan 0-4 m derinlikte örselenmemiş numunenin taşıma gücü $1,25 \mathrm{~kg} / \mathrm{cm}^{2}$ belirlenmiştir. Deprem sonrasında oluşan deformasyonlar, yanal zemin basınç katsayısı, sıkılık derecesi, aşırı konsolidasyon oranı gibi faktörler SPT direncine etki etmektedir [19]. Taşıma Gücü Tasarım Dayanımı için inceleme alanında gözlemlenen killi-siltli zeminin Terzaghi [20], Mayerhorf [21], Hansen [22] ve Vesic [23] tarafindan temel derinliği ve geometrisi ile yatay yüklerin uyguladığı haller için detaylandırılmış ve TBDY'e göre zeminin emniyetli taşıma gücü $1,25 \mathrm{ton} / \mathrm{m}^{2}$ olarak bulunmuştur. Yataklanma katsayısı ise Bowles [24]'e göre 1500 ton $/ \mathrm{m}^{3}$ olarak alınması gerekmektedir. Bu şartlar altında yapılmış yapı temellerinin Radye Temel yapıldığ görülmüştür. İnşaat yükünün zemine üniform olarak yayıldığ1 görülmüş olup zeminde yapı hasarı meydana getirecek bir oturmanın oluşması beklenmemektedir. Radye temellerinde maksimum toplam oturma miktarı, killer için en fazla 12,50 cm olması kabul edilmiştir. İnceleme alanı içinde oturabilecek 5,0 metrelik kil birimler için Konsolidasyon hesabından 5,85 cm değeri bulunmuştur. Sıvılaşma direnci için en yaygın kullanılan arazi deneyi Standart Penetrasyon Deneyi (SPT) olmaktadır. Şişme potansiyelini Seed [25] ve Holtz \& Gibss'e [26] göre Şişme Potansiyeli "Düşük" olduğu hesaplanmıştır. Sahada yapılan ölçümlerde yeraltı suyuna rastlanılmamıştır. Yapılan taşıma gücü tasarım dayanımı, maksimum taban basıncından yüksek olduğundan dolayı zemin iyileştirmesine gerek duyulmamıştır. 


\section{IV.SONUÇLAR}

Kontrollü hasar durumunda can güvenliğinin sağlanması için taşıyıcı sistem elemanlarında hasarın onarılmasının mümkün olduğu ve çok ağır hasar olmaması istenmektedir. TBDY 15. Bölümünde de bahsedildiği üzere yapıların hasar durumları ve hasar bölgelerine ait iç kuvvet-şekil değiştirme grafiği Ek-4'te gösterilmektedir. Yapılan analiz sonucunda aşağıdaki verilere ulaşılmıştır.

- Kirişin hasar oranı: $(\mathrm{IH}=\% 0.0<\% 30)$ ve $(\mathrm{GB}=0)$

- Kolunun hasar oran1: $(\mathrm{IH}=\% 0.0<\% 20)$ ve $(\mathrm{GB}=0)$

- Üst katın kesme oranı: ( $\mathrm{IH}=\% 0.0<\% 40)$ ve $(\mathrm{GB}=0)$

- Plastikleşen kolonun kesme oranı: $(\mathrm{IH}+\mathrm{GB}=\% 0.0<\% 30)$

Yapılan bu çalışmada, İstanbul-Silivri ilçesinde yer alan 2010 yılında inşa edilmiş ve 2 Bodrum + Zemin +4 Normal Kat + Çatı' dan oluşan konut yapısına ait yerinde karot, test çekici, sıyırma, korozyon, zemin sondajı vb. numuneler alınmıştır. Laboratuvar ortamında yapılan deneyler sonucunda birtakım veriler elde edilmiştir. $\mathrm{Bu}$ deneysel veriler kullanılarak bilgisayar ortamında taşıyıcı sistem elemanlarının kapasiteleri belirlenmiş olup, yapının uygulanan deprem kuvveti etkisindeki sınır durumları tespit edilmiştir. TBDY kapsamında, mevcut bir yapının performans analizini belirlemek için doğrusal olmayan statik itme analizi yöntemi sonuçları gösterilmiş olup, yapının yönetmelikçe istenen sınır durumlarını sağlayıp sağlamadığına dair kontrol edilmiştir.

Performans analizi üzerine çalışacak ve güçlendirme projesi hazırlayacak mühendislerin, depreme karşı dayanıklı yapı tasarımı, temel ilkeleri, yönetmeliklerin özünü ve temel kavramlarını, taşıyıcı sistem elemanlarının davranışlarını çok iyi bilmeleri gerekmektedir.

İstanbul İli Silivri İlçesinde bulunan 2010 yılında konut olarak inşa edilmiş bir yapıda, yerinde tarafimızca alınan numunelere, donatı tespitlerine, zemin sondajlarına, deneysel verilere ve bilgisayar ortamında yapılan Doğrusal Olmayan Statik İtme Analizi sonucunda; Deprem hareket düzeyi DD-2 (50 yılda aşılma olasıllığ $\% 10$ ) ve Deprem tasarım sınıfı DTS=1' e göre Türkiye Bina Deprem Yönetmeliği'ne göre konutlar için istenen performans hedefi olan "Kontrollü Hasar" şartını sağladığı görülmüştür. Araştırmacılara kolaylık sağlaması açısından aşamalarıyla belirttiğimiz performans analizi konusunda, farklı düzensiz yapılarda da çalışma sahasının genişletilmesinin uygun olacağı düşünülmektedir.

\section{KAYNAKLAR}

[1] Celep, Z., \& Kumbasar, N. (2004).Deprem Mühendisliğine Giriş ve Depreme Dayanıklı Yapı Tasarımı. Beta Dağıtım, İstanbul.

[2] Chopra, A. K., (2013) Dynamic of Structures and Earthquake Engineering (Forth Edition). Pearson.

[3] Building Seismic Safety Council (1997). NEHRP Guidelines for the Seismic Rehabilitation of Buildings, FEMA-273, Federal Emergency Management Agency, Washington, D.C.

[4] ASCE (2000). "FEMA 356 Prestandard and Commentary for the Seismic Rehabilitation of Buildings", ASCE for the Federal Emergency Management Agency, Washington, D.C., November 2000.

[5] ASCE 41-06, 2006, Seismic Rehabilitation of Existing Buildings, American Society of Civil Engineers, Reston,Virginia.

[6] ATC-40. Seismic Evaluation and Retrofit of Concrete Building. Applied Technology Council, Redwood City,California, 1996.

[7] TBDY (2019), “Türkiye Bina Deprem Yönetmeliğı”, Çevre Şehircilik Bakanlığı. Ankara. 
[8] Barbara, F., Rui, P., Marco, S., \& Roberto, F., (2009). Verification of displacement-based adaptive pushover through multi-ground motion incremental dynamic analyses. Engineering Structures University of Bologna 31, 1789-1799

[9] Tekel, H. (2015), Bina Deprem Güçlendirme Projelerinin Hazırlanması. Tekel İnşaat Mühendislik Kitabı.

[10] Massena, B., Bento, R., \& Degée, H., (2010). Direct Displacement Based Design of a RC Frame-Case of Study. ISSN: 0871-7869.

[11] Zameeruddin M., \& Sangle KK, (2016). Review on Recent developments in the performance- based seismic design of reinforced concrete structures, Structures 6, 119-133.

[12] Li, D., Wei, R., Xing, F., Sui, L., Zhou, Y., \& Wang, W. (2018). Influence of Nonuniform corrosion of steel bars on the seismic behavior of reinforced concrete columns. Constr. Build. Mater., 167, 2032

[13] Deprem Bölgelerinde Yapılacak Binalar Hakkında Yönetmelik, T. C. Bayındırlık ve İskan Bakanlığı, Afet İşleri Genel Müdürlüğü, Deprem Araştırma Dairesi, http/www.deprern.gov.tr, 2007.

[14] T.C. Çevre ve Şehircilik Bakanlığı. (2019). 6306 sayılı Afet Riski Altındaki Alanların Dönüştürülmesi Hakkındaki Kanun,

[15] H. Tekel, (2017), Yapılarda Hasar Tespiti Yöntemler ve Uygulamalar. Tekel İnşaat Mühendislik Kitabı.

[16] Ergün, A., \& Kürklü, G., (2005), Mevcut Betonarme Binalarda Beton Dayanımının Belirlenmesi (Deprem Sempozyumu).

[17] STA4-V14.1 “Structural Analysis for Computer Aided Design” User Guide

[18] Park, C. B., Miller, R. D., Xia, J., \& Ivanov, J. (2001). Seismic characterization of geotechnical sites by multichannel analysis of surface waves (MASW) method. In Tenth International Conference on Soil Dynamics and Earthquake Engineering (SDEE), Philadelphia.

[19] Seed, H. B., Idriss, I. M., \& Arango, I. (1983). Evaluation of liquefaction potential using field performance data. Journal of Geotechnical Engineering, 109(3), 458-482.

[20] Terzaghi, K., (1943). Theoretical Soil Mechanics. Wiley Publishing, New York, USA.

[21] Meyerhof, G. G., (1965). Shallow Foundations State of the Art Review Paper,Proc. ASCE, V. 91.

[22] Brinch, H.J. (1961). A General Formula for Bearing Capacity. Ingenforen (Int. Edition). The Danish Geotechnical Institute, Bulten No. 11, pp. 38-46.

[23] Vesic, A. S. (1973). Analysis of ultimate loads of shallow foundations. Journal of Soil Mechanics \& Foundations Div, 99(sml).

[24] Bowles, J.E., (1988).Foundation Analysis and Design, McGraw Hill, 4th Edition, Singapore

[25] Seed, H. B., \& Lundgren, R. (1962). Prediction of swelling potential for compacted clays. Journal of the soil mechanics and foundations division, 88(3), 53-87.

[26] Fredlund, D. G. (1975). Engineering properties of expansive clays. University of Saskatchewan Transportation and Geotechnical Group. 